\title{
Effect of Aging Treatment before Extrusion on Microstructure and Mechanical Properties of AZ80 Magnesium Alloy
}

\author{
Sun Jing ${ }^{1,2}, \quad$ Zhang Dingfei ${ }^{1,2}, \quad$ Tang Tian $^{1,2}, \quad$ Yu Daliang ${ }^{1,2}, \quad$ Xu Junyao ${ }^{1,2}, \quad$ Pan \\ Fusheng ${ }^{2,3}$
}

${ }^{1}$ College of Materials Science and Engineering, Chongqing University, Chongqing 400045, China; ${ }^{2}$ National Engineering Research Center for Magnesium Alloys, Chongqing University, Chongqing 400044, China; ${ }^{3}$ Chongqing Academy of Science and Technology, Chongqing 401123, China

\begin{abstract}
This paper investigated the effect of aging treatment before extrusion on microstructure and mechanical properties of AZ80 magnesium alloy. Fractural microstructures of the test specimens were also analyzed by scanning electron microscopy. Results show that aging treatment before extrusion can remarkably promote grain refinement; the dispersed $\mathrm{Mg}_{17} \mathrm{Al}_{12}$ particles precipitated from the matrix during aging treatment before extrusion distribute in the grain boundaries; during the subsequent extrusion process these particles can pin grain boundaries migration and lead to fine microstructure; however, with prolonging the aging time, the grain refinement effect is weakened. After aging treatment and subsequent extrusion, the yield strength, tensile strength and elongation are increased. Based on fracture surface analysis, the premature cracks occur around big particles in grain boundaries lead to loss of elongation. The strengthening effect of aging before extrusion in AZ80 magnesium alloy proven in this paper provides a new method for the design of the relatively high-performance magnesium alloys.
\end{abstract}

Key words: magnesium alloy; recrystallization; microstructure; mechanical properties; Zener pinning effect

As the lightest structural materials, magnesium $(\mathrm{Mg})$ alloys are widely used in the automotive, aeronautical and electronic industries for their light weight, high specific strength and specific stiffness, good castability and machinability, excellent damping properties and good electromagnetic shielding ${ }^{[1-3]}$. However, due to their poor mechanical properties, the applications of $\mathrm{Mg}$ alloys have been restricted. The poor mechanical properties of magnesium alloys result from the hexagonally close-packed structure (HCP), so it could not provide five independent slip systems uniform deformation requires at room temperature ${ }^{[4,5]}$. In order to improve the mechanical properties, many strengthening methods have been applied and studied to enhance the strength of magnesium alloys $^{[6-9]}$, such as heat treatment, pre-twinning, alloying and grain refinement. Although great efforts have been done, the mechanical properties of $\mathrm{Mg}$ alloys still cannot satisfy the needs of applications.

In order to enlarge the application field of magnesium alloys, the design of relatively high-performance wrought magnesium alloys has received much attention in recent years. The main reason is that wrought magnesium alloys often perform better mechanical properties than cast magnesium alloys because the deformation process can get rid of pores, homogenize composition and refine grains ${ }^{[10]}$. Mg-Al- $\mathrm{Zn}$ series alloys, one of the most commonly used wrought magnesium alloys including AZ31, AZ80 and AZ91, display good comprehensive mechanical properties and low cost. Among them, the AZ80 alloy has been the well-known commercial magnesium because it exhibits a good combination of medium strength, good corrosion resistance, excellent forging capability and lower price ${ }^{[6]}$. However, the AZ80 alloy still has some deficiencies that result in the limit

$\overline{\text { Received date: July 14, } 2016}$

Foundation item: National Great Theoretic Research Project (2013CB632200); National Natural Science Foundation of China (51474043); Chongqing Municipal Government Project (CSTC2013JCYJC60001)

Corresponding author: Zhang Dingfei, Ph. D., Professor, College of Materials Science and Engineering, Chongqing University, Chongqing 400045, P. R. China, Tel: 0086-23-65112491, E-mail: zhangdingfei@cqu.edu.cn 
of applications, such as the insufficient strength and poor ductility $^{[11]}$.

It is widely believed that fine grain strengthening is the most important method to improve both strength and ductility at the same time ${ }^{[12,13]}$. Controlling the grain size during thermomechanical processing is the key to improving the properties of wrought magnesium alloys ${ }^{[14]}$. As to control the grain size during hot deformation, using the stable pinning particles to pin the migration of grain boundaries and prevent grain growth has been a new method in recent years ${ }^{[15]}$. This mechanism is called Zener pinning effect. A great many works based on this mechanism have been carried out so far. Zener pinning effect that results in grain refinement in magnesium alloys during dynamic recrystallization (DRX) has been applied to pure Mg, AZ31 alloy, AZ61 alloy, AZ91 alloy and ZK60 alloy ${ }^{[16-20]}$. However, up to now, there are few researches on the Zener pining effect on AZ80. What's more, most of the precursory studies focus on revealing the mechanism of Zener pinning effect during hot deformation and pay more attrition to the Zener-Holloman parameter. Hence, in the present study, using the particles precipitating from supersaturated solid solution during aging treatment before extrusion is the key point to refine grain using Zener pinning effect. Aging treatment was carried out before extrusion so that more particles precipitated from matrix during aging and the precipitates pinned grain boundaries migration and prevented grain growth due to Zener pinning effect. In consequence, the effect of aging treatment before extrusion on microstructure and mechanical properties of AZ80 magnesium alloy was investigated.

\section{Experiment}

The material used in the present study was the cast billets of commercial AZ80 magnesium alloy. The chemical composition was confirmed by X-ray fluorescence spectrometer (Shimadzu XRF1800) and the results are shown in Table 1. In order to remove macrosegregation and form supersaturated solid solution, the ingots were homogenized at $420{ }^{\circ} \mathrm{C}$ for $24 \mathrm{~h}$ and then quenched in hot water $\left(\sim 90{ }^{\circ} \mathrm{C}\right)$. After that the quenched alloys were aged at different status to form various precipitates before extrusion. Generally, the discontinuous precipitation would happen in the AZ80 alloy when the aging temperature is below $250{ }^{\circ} \mathrm{C}$ and continuous precipitation would happen when the aging time exceeds $310{ }^{\circ} \mathrm{C}$. Hence, aging at $180{ }^{\circ} \mathrm{C}$ and $330{ }^{\circ} \mathrm{C}$ were conducted in the present study. According to the study of aging process for $\mathrm{AZ80}{ }^{[8]}$, the peak hardness would appear after aging for $10 \mathrm{~h}$. However, with aging time increasing to $30 \mathrm{~h}$, the aging hardness would decrease. It is demonstrated that more precipitates precipitate from the matrix when the aging time exceeds $10 \mathrm{~h}$ and overaging happens when the aging time exceeds $30 \mathrm{~h}$. Therefore, the process selections of aging at $180^{\circ} \mathrm{C}$ for $12 \mathrm{~h}$, $180^{\circ} \mathrm{C}$ for $48 \mathrm{~h}$ and $330^{\circ} \mathrm{C}$ for $48 \mathrm{~h}$ are regarded as the aging
Table 1 Chemical composition of AZ80 alloys (wt\%)

\begin{tabular}{ccccc}
\hline Elements & $\mathrm{Mg}$ & $\mathrm{Al}$ & $\mathrm{Zn}$ & $\mathrm{Mn}$ \\
\hline Content & 90.75 & 8.40 & 0.66 & 0.19 \\
\hline
\end{tabular}

process of discontinuous and peak-aged, discontinuous and overaged, continuous and overaged, respectively. An AZ80 sample without aging treatment before extrusion was also used in these experiments for comparison. The detailed heat treatment schedule is given in Table 2. For the sake of refining the microstructure, the comparison alloy and aged samples were hot extruded to bars with the diameter of $16 \mathrm{~mm}$ at 330 ${ }^{\circ} \mathrm{C}$ with the extrusion ratio of $25: 1$ at a ram speed of $1 \mathrm{~mm} \cdot \mathrm{s}^{-1}$. Both the comparison and as-aged samples were pre-heated at $330{ }^{\circ} \mathrm{C}$ for $1 \mathrm{~h}$ before extrusion.

The microstructures of the samples before and after extrusion were observed by an optical microscope (OM, OLYMPUS OLS4000). The precipitates evolution of diverse heat treatment states was examined by a scanning electron microscope (TESCAN VEGA 3 LMH SEM) (SEM). After extrusion, uniaxial tensile tests were performed on a SANS CMT-5105 electronic testing machine at the strain rate of $2 \times 10^{-3} \mathrm{~s}^{-1}$ at room temperature. The specimens for tensile tests were smooth dog bone-shaped with a gauge size of $5 \mathrm{~mm}$ in diameter and $35 \mathrm{~mm}$ in length and machined from the as-extruded bars under different heat treatment conditions. The tensile direction was parallel to the extrusion direction and the yield stress was determined as the $0.2 \%$ offset. Three tensile specimens were prepared for each condition and the average value was adopted. Afterwards, the fracture images of the tensile specimens were characterized by scanning electron microscopy (TESCAN VEGA 3 LMH SEM).

\section{Results and Discussion}

\subsection{Microstructure before extrusion}

Optical microstructure changes of AZ80 alloys under different conditions before extrusion are shown in Fig. 1. It should be noted that the grain size of the specimens subjected to aging treatment is a little bit larger than that of the comparison one. Except for that, there is no obvious difference among the specimens in various states. Fig.2 depicts the SEM morphologies of the AZ80 under different conditions before extrusion. As is shown in Fig.2a, few precipitates can be found in the specimen without aging treatment. After aging treatment, large quantities of second phases precipitate from supersaturated solid solution specimens. These precipitates

Table 2 Heat treatment process for the extruded AZ80 alloy

\begin{tabular}{cc}
\hline Designation & Heat treatment process \\
\hline H1 & $\mathrm{ST}^{\mathrm{a}}$ at $420{ }^{\circ} \mathrm{C} / 6 \mathrm{~h}, \mathrm{WQ}^{\mathrm{b}}$ \\
$\mathrm{H} 2$ & $\mathrm{ST}$ at $420{ }^{\circ} \mathrm{C} / 6 \mathrm{~h}, \mathrm{WQ}$, aging at $180{ }^{\circ} \mathrm{C} / 12 \mathrm{~h}$ \\
$\mathrm{H} 3$ & $\mathrm{ST}$ at $420{ }^{\circ} \mathrm{C} / 6 \mathrm{~h}, \mathrm{WQ}$, aging at $180{ }^{\circ} \mathrm{C} / 48 \mathrm{~h}$ \\
$\mathrm{H} 4$ & $\mathrm{ST}$ at $420{ }^{\circ} \mathrm{C} / 6 \mathrm{~h}, \mathrm{WQ}$, aging at $330{ }^{\circ} \mathrm{C} / 48 \mathrm{~h}$ \\
\hline
\end{tabular}

${ }^{\mathrm{a}} \mathrm{ST}$, solution treated; ${ }^{\mathrm{b}} \mathrm{WQ}$, water quenched 


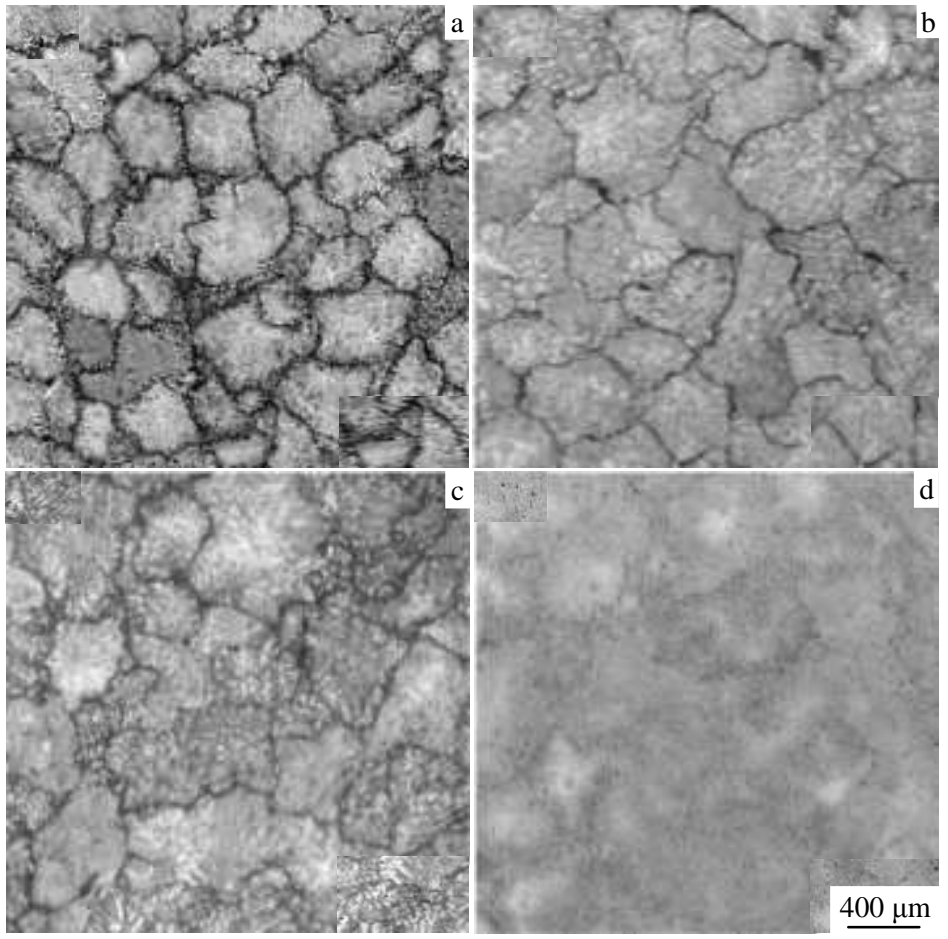

Fig.1 Optical microstructures of AZ80 alloy under different conditions before extrusion: (a) H1, (b) H2, (c) H3, and (d) H4

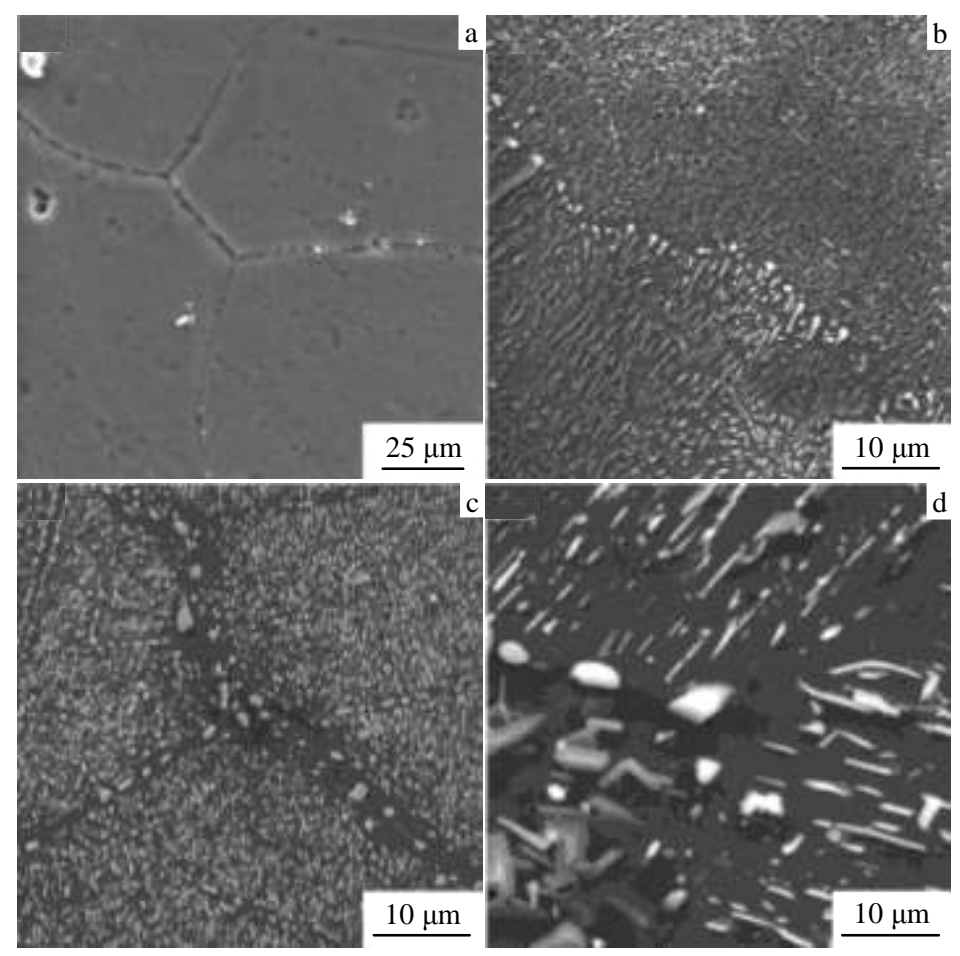

Fig.2 SEM of AZ80 alloy under different conditions before extrusion: (a) H1, (b) H2, (c) H3, and (d) H4

distribute in the grain interior and grain boundaries, and the amount of precipitates in the grain interior is more than that in the grain boundaries (Fig. 2b 2d)). It can be seen clearly that the precipitates get much coarser with elevating aging temperature or/and prolonging the aging time. Besides, it is noteworthy that the precipitates in the interior of the grains 
retain a specific orientation relationship with matrix. Many researchers have reported this specific relationship in detail ${ }^{[21,22]}$.

\subsection{Microstructure after extrusion}

Fig.3 presents the optical micrographs of transverse and longitudinal directions under different conditions after extrusion. Compared with the specimens before extrusion, the grains of all the specimens get refined remarkably due to the occurrence of DRX during hot extrusion. Fig.3a shows the microstructure of the specimen without aging treatment (H1) seen from transverse direction. It consists of approximately equiaxed grains with the size of the range from $20 \mu \mathrm{m}$ to 40 $\mu \mathrm{m}$. Fig. $3 \mathrm{c}, 3 \mathrm{e}$ and $3 \mathrm{~g}$ show the microstructures of specimens aged at $180{ }^{\circ} \mathrm{C}$ for $12 \mathrm{~h}(\mathrm{H} 2), 180{ }^{\circ} \mathrm{C}$ for $48 \mathrm{~h}(\mathrm{H} 3), 330{ }^{\circ} \mathrm{C}$ for $48 \mathrm{~h}(\mathrm{H} 4)$ seen from transverse direction, respectively. The grains of the specimens subjected to aging treatment are much finer than that without aging treatment (H1). Particularly in Fig. 3c, it can be seen that the grain is fine and uniform. With prolonging the aging time or elevating the aging temperature, the inhomogeneous microstructures can be observed. Fig. $3 \mathrm{e}$ and $3 \mathrm{~g}$ show that a small number of large grains $(\sim 10 \mu \mathrm{m})$ are surrounded by regions of fine equiaxed grains $(\sim 3 \mu \mathrm{m})$. From the microstructures under different conditions seen from longitudinal direction (Fig. 3b, 3d, 3f, 3h), they are characterized by some large elongated grains (stripes) along the extrusion direction (ED), surrounded by regions of fine equiaxed grains. Meanwhile, the trend of microstructures' changes seen from longitudinal direction is corresponding to that seen from transverse direction.

SEM images of specimens under different conditions are shown in Fig.4. Apparently, the variation of grain size is consistet with that indicated in the optical microstructures (Fig. 3). Compared with Fig.2, the evolution of precipitates is of great significance. After extrusion, most precipitates are dispersed in the grain boundaries, and the amount of precipitates in the grain interior declines accordingly. Simultaneously, the specific orientation relationship between the precipitates and matrix disappears. In Fig. 4a, a spot of precipitates distribute in the grain boundaries. Fig. $4 \mathrm{~b}$ shows almost all the precipitates of the specimen subjected to aging treatment at $180{ }^{\circ} \mathrm{C}$ for $12 \mathrm{~h}$, which were initially segregated in the grain interior, distribute in the grain boundaries homogeneously. The occurrence of precipitates segregation in the specimens aged at $180{ }^{\circ} \mathrm{C}$ for $48 \mathrm{~h}$ and $330{ }^{\circ} \mathrm{C}$ for $48 \mathrm{~h}$ results from long time overaging (Fig. $4 \mathrm{c}$ and $4 \mathrm{~d}$ ). Fine particles' effect of pinning boundary migration is well known and widely observed in magnesium alloys ${ }^{[23]}$. Bai Jing et al. ${ }^{[24]}$ systematically researched $\mathrm{Mg}-4 \mathrm{Al}-2 \mathrm{Sr}-0.3 \mathrm{Mn}$ and $\mathrm{Mg}-4 \mathrm{Al}-$ $2 \mathrm{Sr}-1 \mathrm{Ca}-0.3 \mathrm{Mn}$ and found that the as-extruded $\mathrm{Mg}-4 \mathrm{Al}-2 \mathrm{Sr}-$ $1 \mathrm{Ca}-0.3 \mathrm{Mn}$ exhibited finer microstructure than as-extruded $\mathrm{Mg}-4 \mathrm{Al}-2 \mathrm{Sr}-0.3 \mathrm{Mn}$. Further research indicated that a small amount of $\mathrm{Ca}$ addition had an effect on microstructural refinement for $\mathrm{Mg}-\mathrm{Al}-\mathrm{Sr}$ based alloys. To be specific, the tiny $\mathrm{Al}_{2} \mathrm{Ca}$ particles exerted restraining forces upon grain

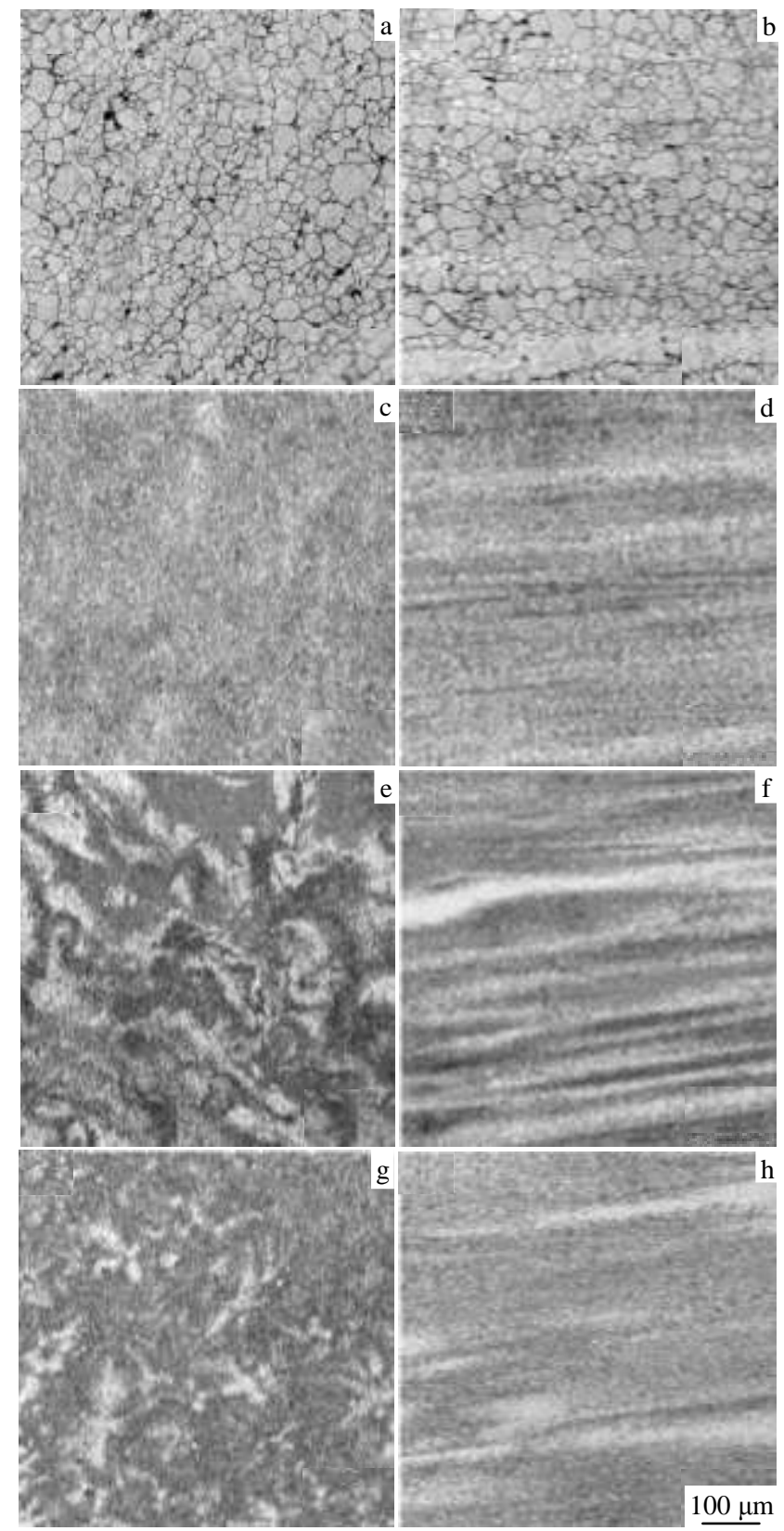

Fig.3 Optical micrographs of transverse (a, c, e, g) and longitudinal (b, $\mathrm{d}, \mathrm{f}, \mathrm{h}$ ) direction for AZ80 alloy under different conditions after extrusion: (a, b) H1, (c, d) H2, (e, f) H3, and (g, h) H4

boundaries during recrystallization and were effective in decreasing the grain boundary mobility. The study of S. W. $\mathrm{Xu}$ et al. ${ }^{[19]}$ demonstrated that the $\mathrm{Mg}_{17} \mathrm{Al}_{12}$ precipitates had pinning effect which was greatly influenced by compression temperature. Hence, a pronounced phenomenon in Fig.4c and $4 \mathrm{~d}$ that the grain size gets finer with the increase of the precipitates in the grain boundaries due to the Zener pinning effect has been observed. The precipitates dispersed in the grain boundaries after extrusion have the effect of pining boundary migration and prevent grain growth availably 

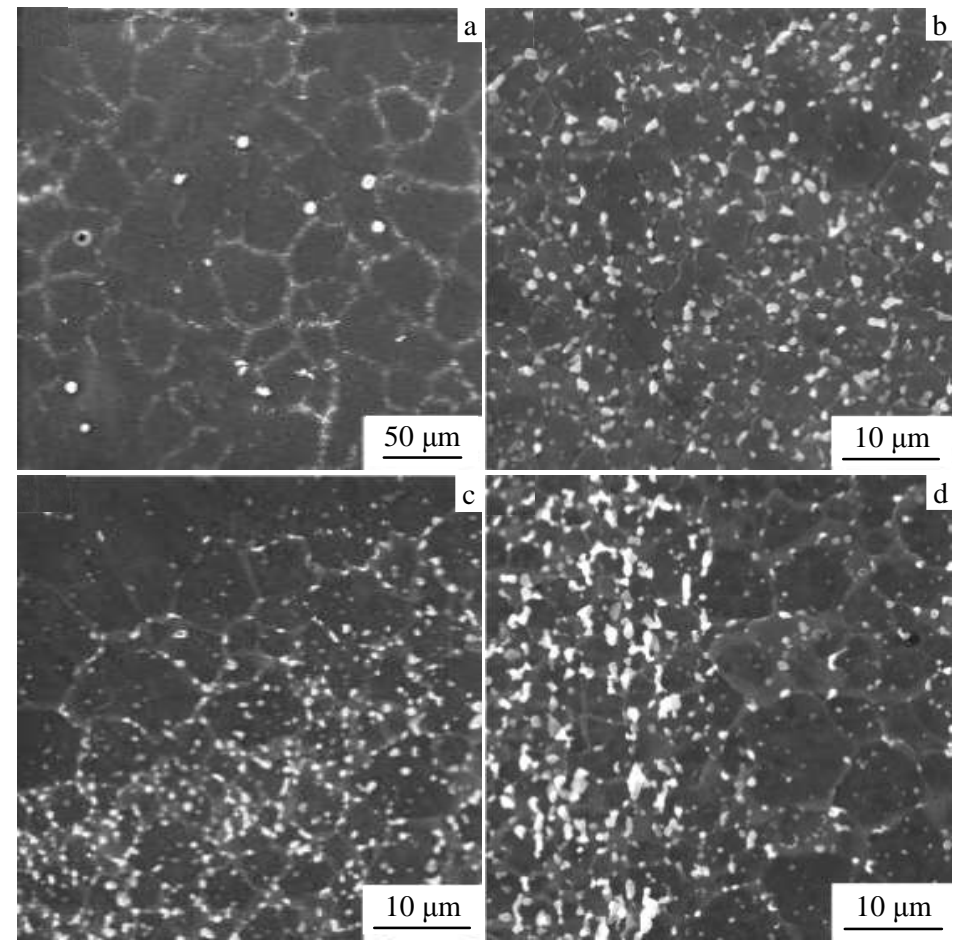

Fig. 4 SEM of AZ80 alloy under different conditions after extrusion: (a) H1, (b) H2, (c) H3, and (d) H4

during the dynamic recrystallization. The effect is proportional to the amount of precipitates approximately. From Fig. $4 \mathrm{c}$ and $4 \mathrm{~d}$, the grains with more precipitates in the grain boundaries are fine, on the contrary, the grains with less precipitates in the grain boundaries are coarse. This is the reason why the optical microstructures of the specimens aged at $180{ }^{\circ} \mathrm{C}$ for $48 \mathrm{~h}$ and $330{ }^{\circ} \mathrm{C}$ for $48 \mathrm{~h}(\mathrm{H} 3, \mathrm{H} 4)$ are inhomogeneous (Fig. 3e, 3g).

\subsection{Mechanical properties}

The columnar sections of mechanical property indexes of as-extruded specimens under different conditions obtained through the uniaxial tensile tests are presented in Fig.5. Yield strength and tensile strength of the specimens aged at $180{ }^{\circ} \mathrm{C}$ for $12 \mathrm{~h}(\mathrm{H} 2), 180{ }^{\circ} \mathrm{C}$ for $48 \mathrm{~h}(\mathrm{H} 3)$ and $330{ }^{\circ} \mathrm{C}$ for $48 \mathrm{~h}(\mathrm{H} 4)$ are 244 and 360, 236 and 354, 230 and $343 \mathrm{MPa}$, respectively. In comparison with 213 and $322 \mathrm{MPa}$ of the specimen without aging treatment, yield strength and tensile strength of the specimens with aging treatment increase sharply. The elongation of the specimens without aging treatment (H1), aged at $180{ }^{\circ} \mathrm{C}$ for $12 \mathrm{~h}(\mathrm{H} 2), 180{ }^{\circ} \mathrm{C}$ for $48 \mathrm{~h}(\mathrm{H} 3)$ and $330{ }^{\circ} \mathrm{C}$ for $48 \mathrm{~h}(\mathrm{H} 4)$ is $12.1 \%, 14.3 \%, 12.9 \%$ and $9.5 \%$, respectively. The results accord with the microstructures of all the specimens under different conditions. It has been reported that fine grains help to prevent the formation of deformation twins and activate dislocations on non-basal planes which will lead to the enhancement of strength as well as ductility ${ }^{[25]}$. Thus, the yield strength, tensile strength and elongation of the specimen aged at $180{ }^{\circ} \mathrm{C}$ for $12 \mathrm{~h}(\mathrm{H} 2)$ are all improved because the microstructure gets finer and more uniform.

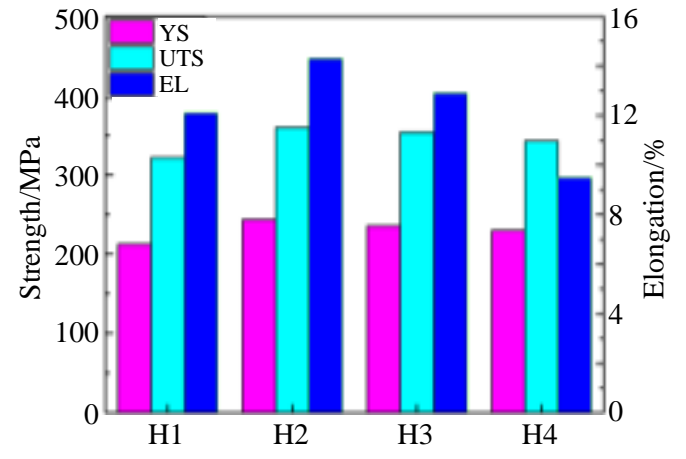

Fig.5 Columnar sections of mechanical property indexes of asextruded AZ80 alloy under different conditions

Moreover, the Zener pinning effect of the precipitates distributing in the grain boundary during dynamic recrystallization is another important reason for the improvement of mechanical property indexes. Certainly, the enhancement of mechanical properties for AZ80 alloy improves the cost of machining to some extent. However, in some particular situations for the applications of magnesium alloys, compared with the increase of machining cost caused by the improvement of mechanical properties, the improvement of comprehensive mechanical properties results from the refinement of grains will expand the application range of AZ80 alloy and bring greater economic benefits.

\subsection{Fracture morphology}


Fig. 6 shows the fracture morphologies of the specimens under $\mathrm{H} 1, \mathrm{H} 2, \mathrm{H} 3$ and $\mathrm{H} 4$ conditions after tensile test. The fracture morphologies of all the specimens under different conditions exhibit hybrid fracture of cleavages and dimples. Compared with the specimen without aging treatment, dimples become more and cleavages become less by aging at $180{ }^{\circ} \mathrm{C}$ for $12 \mathrm{~h}$. Whereafter, with the aging time prolonged and/or the aging temperature elevated, dimples become less. Meanwhile, in comparison with the fracture morphologies of the specimens under other heat treatment conditions, some coarse and broken precipitates in the grain boundaries are presented in the fracture morphology of the specimen aged at $330{ }^{\circ} \mathrm{C}$ for $48 \mathrm{~h}$. It is acknowledged that coarse precipitates can lead to the stress concentration and crack initiation and microcracks tend to initiate in the $\mathrm{Mg} / \mathrm{Mg}_{17} \mathrm{Al}_{12}$ interface and even in the $\mathrm{Mg}_{17} \mathrm{Al}_{12}$ particles ${ }^{[25,26]}$. Thus, based on the previous analysis, the coarsening of precipitates, segregation of precipitates and inhomogeneity of grains (Fig.3g, 3h and Fig.4d) are the reasons why the elongation of the as-extruded specimen under $\mathrm{H} 4$ conditions is lower than that of other conditions. It is well known that the precipitates distributing in the grain boundaries and interiors have the effect of pinning grain boundary migration and strengthening the $\alpha-\mathrm{Mg}$ matrix ${ }^{[27]}$. Therefore, improving deformability of AZ80 by grain boundary migration and non-basal slip induced by grain rotation is strictly limited so as to reduce the ductility and elongation. However, the strength and elongation are both improved of the specimens under $\mathrm{H} 2$ and $\mathrm{H} 3$ conditions in this study. Based on Fig. 3 and Fig.4, the precipitates that disperse in the grain boundaries dominantly after the process of aging

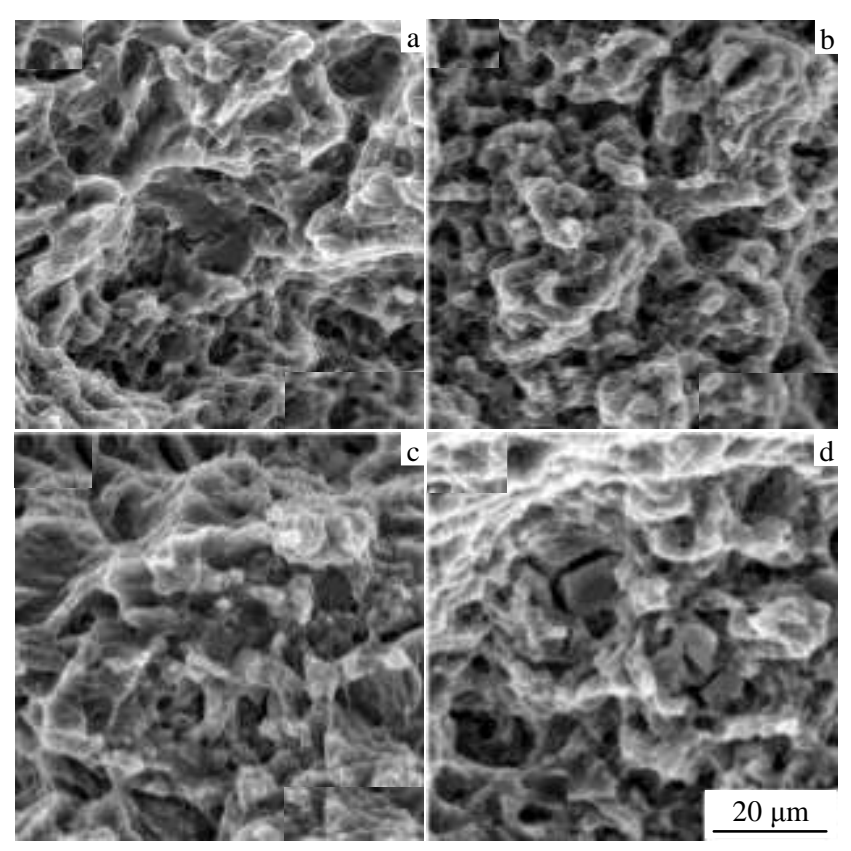

Fig.6 Fracture morphologies of AZ80 under different conditions: (a) $\mathrm{H} 1$, (b) $\mathrm{H} 2$, (c) $\mathrm{H} 3$, and (d) $\mathrm{H} 4$ treatment and extrusion pin boundary migration and prevent grain growth during the dynamic recrystallization. Thus, the grains of the specimens subjected to aging treatment are finer than those of solid solution state. The strength and elongation are both improved accordingly.

\section{Conclusions}

1) The grains of AZ80 magnesium alloy can be refined obviously by aging before extrusion. But with prolonging aging time and/or elevating aging temperature, the grains grow up and become inhomogeneous.

2) The mechanical properties of AZ80 can be improved by aging before extrusion. In particular, both strength and elongation are improved simultaneously. Long aging time and/or high aging temperature lead to the decrease of elongation. To sum up, the most optimized process parameters is aging at $180{ }^{\circ} \mathrm{C}$ for $12 \mathrm{~h}$.

3) The mechanism of optimizing structure and improving mechanical properties by aging before extrusion is Zener pinning effect. The precipitates dispersed in the grain boundaries pin boundary migration and prevent grain growth effectively during the dynamic recrystallization.

\section{References}

1 Mordike B L, Ebert Tü. Materials Science and Engineering A[J], 2001, 302: 37

2 Luo Alan A. Journal of Magnesium and Alloys[J], 2013(1): 2

3 Chang Hai, Wang Xiaojun, Hu Xiaoshi et al. Rare Metal Materials and Engineering [J], 2014, 43(8): 1821

4 Li Xiaohui, Feng Xiaowei, Wang Shuncheng et al. Rare Metal Materials and Engineering[J], 2014, 43(12): 2927

5 Kaneko Junichi, Sugamata Makoto, Numa Masahiro et al. Journal of the Japan Institute of Metals(Japan)[J], 2000, 64: 141

6 Zhao Degang, Wang Zhenqing, Zuo Min et al. Materials \& Design[J], 2014, 56: 589

7 Song Bo, Guo Ning, Liu Tingting et al. Materials \& Design[J], 2014, 62: 352

8 Jiang Luyao, Zhang Dingfei, Fan Xiaowei et al. Journal of Alloys and Compounds[J], 2015, 620: 368

9 Del Valle J A, Carreño Fernando, Ruano Oscar Antonio. Acta Materialia[J], 2006, 54: 4247

10 Kubota K, Mabuchi M., Higashi K. Journal of Materials Science[J], 1999, 34: 2255

11 Wang P C, Lin M C, Lin H C et al. Materials Science and Engineering A[J], 2010, 527: 4076

12 Yang Mingbo, Guo Tingzhang, Li Hongliang et al. Rare Metal Materials and Engineering [J], 2013, 42(8): 1541

13 Xu Tiancai, Peng Xiaodong, Jiang Junwei et al. Rare Metal Materials and Engineering[J], 2014, 43(8): 1815

14 Robson J D, Henry D T, Davis B. Materials Science and Engineering A[J], 2011, 528: 4239

15 Bate P. Acta Materialia[J], 2001, 49: 1453

16 Sivakesavam O, Rao I S., Prasad Uvrk. Materials Science and 
Technology[J], 1993, 9: 805

17 Kim W J, Lee J B, Kim W Y et al. Scripta Materialia[J], 2007, 56: 309

18 Watanabe Hiroyuki, Tsutsui Hirosuke, Mukai Toshiji et al. Materials Transactions-JIM[J], 2001, 42: 1200

19 Xu S W, Matsumoto N, Kamado S et al. Scripta Materialia[J], 2009, 61: 249

20 Kaibyshev R O, Galiev A M, Sokolov B K. Physics of Metals and Metallography[J], 1994, 78: 209

21 Celotto S. Acta Materialia[J], 2000, 48: 1775

22 Lai Wei-Jen, Li Yi-Yun, Hsu Yung-Fu et al. Journal of Alloys and
Compounds[J], 2009, 476: 118

23 Wang Shouren, Ma Ru, Yang Liying et al. Journal of Materials Science [J], 2011, 46: 3060

24 Bai Jing, Sun Yangshan, Xue Feng et al. Scripta Materialia[J], 2006, 55: 1163

25 Koike J, Kobayashi T, Mukai T et al. Acta Materialia[J], 2003, 51: 2055

26 Lü Y Z, Wang Q D, Ding W J et al. Materials Letters[J], 2000, 44: 265

27 Li Mingzhao, Li Cong, Liu Xuguang et al. Rare Metal Materials and Engineering [J], 2009, 38: 7

\title{
挤压前的时效处理对 AZ80 镁合金组织和力学性能的影响
}

\author{
孙 静 ${ }^{1,2}$, 张丁非 ${ }^{1,2}$, 唐 甜 ${ }^{1,2}$, 余大亮 ${ }^{1,2}$, 胥钧耀 ${ }^{1,2}$, 潘复生 ${ }^{2,3}$ \\ (1. 重庆大学 材料科学与工程学院, 重庆 400045) \\ (2. 重庆大学 国家镁合金材料工程技术研究中心, 重庆 400044) \\ (3. 重庆市科学技术研究院, 重庆 401123)
}

\begin{abstract}
摘 要: 主要研究了挤压前的时效处理工艺对 AZ80 镁合金显微组织和力学性能的影响, 同时利用扫描电子显微镜对试样断口进行分析。 结果表明: 挤压前时效处理可以明显细化晶粒; 时效过程中析出的 $\mathrm{Mg}_{17} \mathrm{Al}_{12}$ 粒子弥散分布在晶界处, 在动态再结晶过程中起到阻碍晶界 移动、阻止晶粒长大、细化组织的作用; 随着时效时间的延长或者时效温度的升高, 晶粒细化效果减弱; 对时效后合金进行挤压, 试样 的屈服强度、抗拉强度和延伸率均提高。通过对断口形貌的分析发现, 早期裂纹产生于晶界处粗大的第二相周围, 导致了拉伸过程中延 伸率的下降。挤压前时效处理对 AZ80 的强化效果为高性能镁合金的设计和开发提供了一种全新的思路。
\end{abstract}

关键词: 镁合金; 再结晶; 显微组织; 力学性能; 齐纳钉扎效应

作者简介: 孙 静, 女, 1991 年生, 硕士生, 重庆大学材料科学与工程学院, 重庆 400045, 电话: 023-65112491, E-mail: sunsunjing2010@163.com 